\title{
Targeting hedgehog signaling in cancer: research and clinical developments
}

Jingwu Xie

Christopher M Bartels

Scott W Barton

Dongsheng Gu

Wells Center for Pediatric Research, Division of Hematology and Oncology, Department of Pediatrics, Indiana University Simon Cancer Center, Indiana University, Indianapolis, IN, USA
Correspondence: Jingwu Xie

Cancer Research Institute,

Room R4-327, I040W.Walnut Street,

Indianapolis, IN 46202, USA

Tel +I 3172783999

Fax +I 3172748046

Email jinxie@iu.edu
This article was published in the following Dove Press journal:

OncoTargets and Therapy

9 October 2013

Number of times this article has been viewed

\begin{abstract}
Since its first description in Drosophila by Drs Nusslein-Volhard and Wieschaus in 1980, hedgehog $(\mathrm{Hh})$ signaling has been implicated in regulation of cell differentiation, proliferation, tissue polarity, stem cell maintenance, and carcinogenesis. The first link of $\mathrm{Hh}$ signaling to cancer was established through studies of Gorlin syndrome in 1996 by two independent teams. Later, it was shown that Hh signaling may be involved in many types of cancer, including skin, leukemia, lung, brain, and gastrointestinal cancers. In early 2012, the US Food and Drug Administration approved the clinical use of Hh inhibitor Erivedge/vismodegib for treatment of locally advanced and metastatic basal cell carcinomas. With further investigation, it is possible to see more clinical applications of Hh signaling inhibitors. In this review, we will summarize major advances in the last 3 years in our understanding of Hh signaling activation in human cancer, and recent developments in preclinical and clinical studies using $\mathrm{Hh}$ signaling inhibitors.
\end{abstract}

Keywords: hedgehog, smoothened, PTCH1, cancer, signal transduction, clinical trials, animal model

\section{Introduction}

Remarkable progress has been made since the hedgehog (Hh) mutant phenotype was first described in fruit fly in $1980 .{ }^{1}$ Three vertebrate homologues of Hh and their receptors were identified in the $1990 \mathrm{~s}^{2-6}$ As an essential pathway during development, the Hh pathway is critical for maintaining tissue polarity and stem cell population. The first link between Hh signaling and cancer was shown in tumor-prone Gorlin syndrome in 1996..$^{711}$ In early 2012, Hh signaling inhibitor GDC-0449 (Erivedge/ vismodegib; Hoffmann-La Roche Ltd, Basel, Switzerland) was approved by the US Food and Drug Administration for treatment of locally advanced and metastatic basal cell carcinomas (BCCs).

The general signaling mechanisms of the Hh pathway are conserved from flies to humans. ${ }^{12}$ Mammalian Hh signaling molecules include ligands (sonic Hh, Indian Hh, and desert $\mathrm{Hh}$ ), patched receptors (PTCH1, PTCH2), signal transducer smoothened (SMO), and transcription factors (Gli1, Gli2, Gli3) (see Figure 1). In the absence of ligands, SMO serves as the key signal transducer, whose function is inhibited by another transmembrane protein patched (PTCH1). Upon binding of an active $\mathrm{Hh}$ ligand, this inhibition is released, allowing SMO to signal downstream, eventually leading to activation of Gli transcription factors. Gli molecules can bind the specific consensus sequences located in the promoter region of the target genes to regulate target gene expression. ${ }^{13,14}$ 


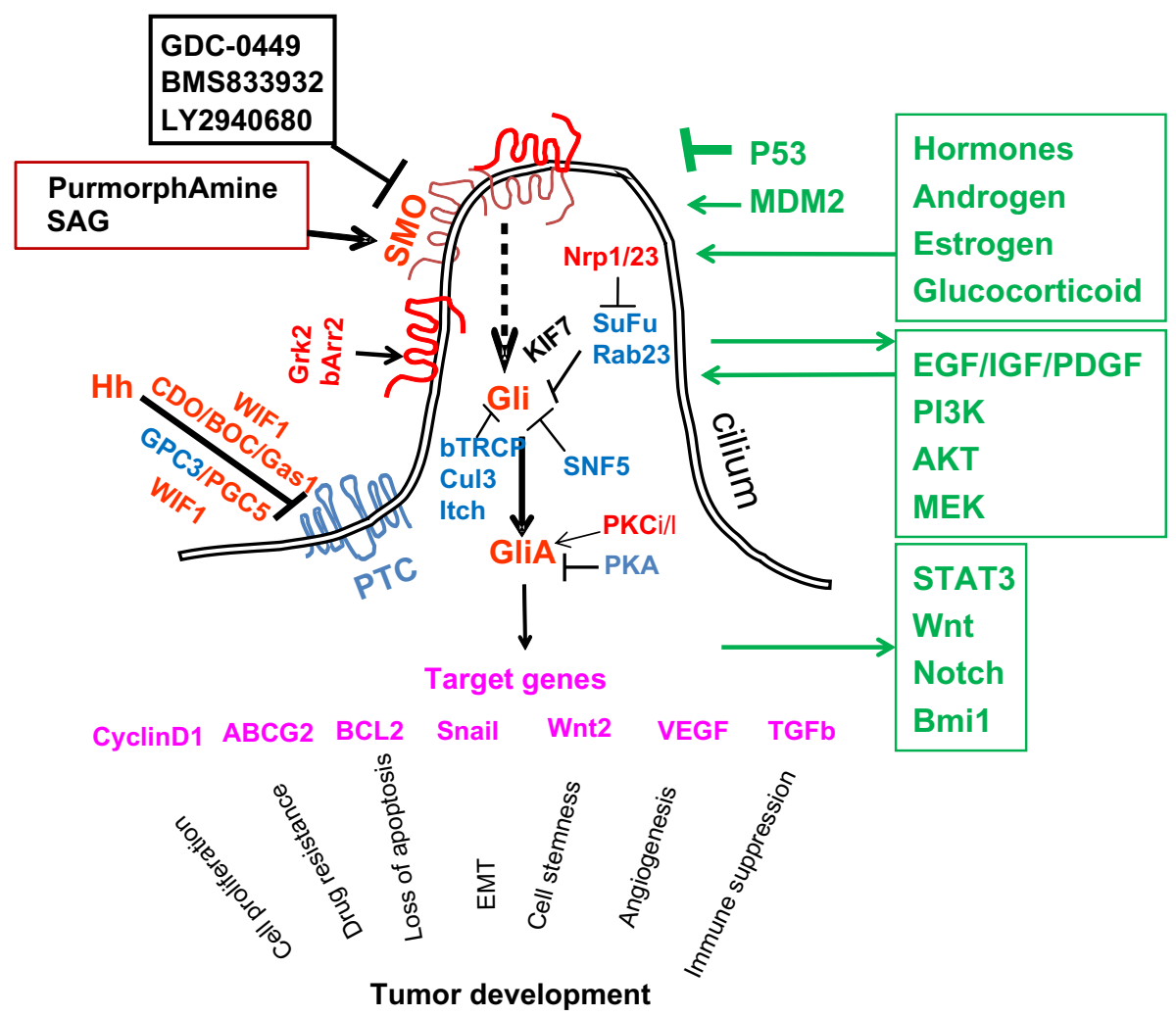

Figure I A diagram of hedgehog (Hh) signaling in mammalian cells. Smoothened (SMO) is the key signal transducer of the Hh pathway. In the absence of the Hh ligands, Hh receptor patched (PTC) is thought to be localized in the cilium to inhibit SMO signaling. Coreceptors of Hh include CDO (cell adhesion molecule-related/downregulated by oncogenes), brother of CDO (BOC), Gas I, glypican 3, (GPC3), and GPC5. Wnt inhibitory factor-I (WIFI) can also regulate Hh signaling through association with CDO, BOC, or GPC5. Gli molecules are processed with the help of suppressor of fused (SuFu)/KIF7, $\beta$-TRCP molecules into repressor forms, which turn off the Hh signaling pathway. Other negative regulators of Gli molecules include Rab23, protein kinase A (PKA), SuFu, tumor suppressor sucrose nonfermenting 5 (SNF5), Culin 3 (Cul3), and itchy E3 ubiquitin ligase (Itch) through regulation Gli protein modifications, nuclear-cytoplasm shuttling, as well as transcriptional activities. In the presence of Hh, PTC is thought to be shuttled out of cilium and is unable to inhibit SMO. The ciliary localization of SMO is thought to require $\beta$-arrestin 2 ( $\beta$ Arr2), and G protein coupled receptor kinase 2 (GRK2). Hh reception promotes SMO conformational changes to form dimers. Gli molecules are now processed to active forms (GliA), which will activate the Hh target genes. This process can be inhibited by KIF7 and SuFu. Protein kinase $C$ isoform $1 / \lambda(\mathrm{PKCl} / \lambda)$ is known to positively regulate Gli transcriptional activity. Positive regulators are in red, negative regulators are in blue, and target genes are in pink. KIF7 can function (in black) as a negative regulator or a positive regulator. The interacting pathways with the Hh pathway are in green. Although the role of cilium for Hh signaling during embryonic development is well established, cancer cells generally lack cilia. It has been demonstrated that lack of cilia prevents development of basal cell carcinomas in mice. It is not clear whether this is true for all other types of Hh signaling-associated cancer.

Abbreviations: EGF, epidermal growth factor; EMT, epithelial-mesenchymal transition; IGF, insulin-like growth factor; PDGF, platelet-derived growth factor; TGF $\beta$, transforming growth factor $\beta$; VEGF, vascular endothelial growth factor; GDC0449, synthetic small molecules targeting at SMO signaling; BMS833932, synthetic small molecules targeting at SMO signaling; LY2940680 synthetic small molecules targeting at SMO signaling; SAG, smoothened agonist; MDM2, Mouse double minute 2 homolog; PI3K, Phosphatidylinositide 3-kinases; AKT, homolog of viral oncogene v-AKT; MEK, MAPK or ERK kinase; Stat3, signal transducer and activator of transcription 3; Wnt, wingless homolog; ABCG2, ATP-binding cassette sub-family G member 2; BCL2, B-cell lymphoma 2; bTRCP, beta-transducin repeat containing protein.

In the last 3 years, there has been significant progress regarding Hh signaling and its significance in cancer development and therapeutics. The total number of publications on Hh signaling in the last 3 years is close to $30 \%$ of all Hh-related publications, and progress has been made in the following areas: 1) better understanding of Hh signal transduction and the associated target genes, 2) more reliable mouse models linking Hh signaling to human malignancies, 3) better understanding of Hh signaling mechanisms during cancer development and metastasis, 4) an increasing number of clinical and preclinical studies on cancer treatment using Hh signaling inhibitors, and 5) emerging evidence of Hh signaling in supporting residual cancer cells and cancer stem cells.

\section{Signal transduction of the Hh pathway}

All $\mathrm{Hh}$ proteins are secreted molecules, functioning at short range on nearby cells or at long range to distant cells during development. ${ }^{15-17}$ Hh protein precursors undergo post-translational modifications (autocleavage to release the $\mathrm{N}$-terminal fragment $[\mathrm{HhN}]$, covalently binding to a cholesterol moiety at the $\mathrm{C}$-terminal end, and palmitoylation by a palmitoylacyltransferase at the $\mathrm{N}$-terminus of $\mathrm{HhN}$ ). ${ }^{18-21}$ Molecules involved in Hh protein transport and distribution include the transmembrane transporter-like protein dispatched (Disp) ${ }^{22-24}$ metalloproteinases, ${ }^{25}$ the heparan sulfate proteoglycans Dally-like (Dlp) and Dally ${ }^{26,27}$ or their regulators, ${ }^{28}$ as well as enzymes such as sulfateless and tout velu. ${ }^{29-31}$ 
Figure 1 shows the mammalian Hh signaling pathway with major players in the diagram. Several molecules are engaged in reception of Hh ligands, with patched (PTC, one PTC in fly, and two PTCs in vertebrates: PTCH1 and PTCH2) as the major receptor. ${ }^{32}$ Studies from cultured cells indicate that PTC inhibits SMO at a substochiometric concentration. ${ }^{33}$ Hh-interacting protein (HIP) can compete with PTC on $\mathrm{Hh}$ binding, resulting in negative regulation of $\mathrm{Hh}$ signaling. ${ }^{34} \mathrm{On}$ the other hand, interference $\mathrm{Hh}$ or its vertebrate homologues cell adhesion molecule related/downregulated by oncogenes (CDO) and BOC (brother of CDO), GAS1, and glypican-3 (GPC3) serve as coreceptors of Hh. ${ }^{35-42}$ In contrast to the inhibitory effect of glypican-3, glypican-5 (GPC5) and other heparan sulfate proteoglycans are shown to stimulate $\mathrm{Hh}$ signaling by promoting binding of sonic $\mathrm{Hh}$ to $\mathrm{PTCH} 1{ }^{43,44}$ The effect of GPC5 and interference Hh homologues requires another secreted extracellular molecule: Wnt inhibitory factor-1 (WIF1). ${ }^{45,46}$ It is still not entirely clear how binding of Hh proteins results in the pathway activation. It is proposed that PTC limits SMO signaling via transporting endogenous small molecules specifically targeted to SMO. Candidates of these small molecules include PI4P, lipoproteins, and provitamin D3. ${ }^{47-50}$ It is currently not very clear how these molecules regulate SMO signaling.

It is now known that glucocorticoid molecules can modulate SMO signaling through regulating its ciliary localization. ${ }^{51}$ Several recent reports support SMO to G protein coupling, ${ }^{52-55}$ but the physiological relevance of the G protein coupling of SMO in carcinogenesis has not been convincingly demonstrated. $\mathrm{G} \alpha$ can also regulate $\mathrm{Gli}$ proteins independent of SMO. ${ }^{56}$ It is quite clear that two important events occur during SMO signaling in mammalian cells. First, SMO protein undergoes conformational change to favor SMO signaling, ${ }^{57}$ although the regulatory mechanism underlying this conformational change is not clear. Second, ciliary translocation of mammalian SMO protein is critical for Hh signaling. ${ }^{58-63}$ Several reports now link neuropilin $1 / 2$ (Nrp1/2) to SMO signaling. ${ }^{64-67}$

Several molecules are identified to be genetically downstream of SMO in Drosophila, including COS2, suppressor of fused $(\mathrm{SuFu})$, and fused. A COS2 homologue, kinesin like-protein KIF7, functions in the Hh pathway but not directly associated with SMO, ${ }^{68-72}$ suggesting that KIF7 does not contain all COS2 functions in vertebrates. In contrast, the phenotype of fused ${ }^{-/-}$mice is very different from Shh null mice, ${ }^{73-75}$ indicating that fused is not critical for Hh signaling during early embryonic development in mice.
In addition to the Drosophila homologues, mammalian cells have several novel cytoplasmic regulators of $\mathrm{Hh}$ signaling, including Rab23 ${ }^{76}$ and tectonic. ${ }^{77}$ Rab23 and tectonic are all negative regulators downstream of SMO. We have shown that Rab23 is involved in Gli-SuFu interaction ${ }^{78}$ (see Figure 1). Unlike many Rab proteins, we found that Rab23 is localized both in the nucleus and in cytoplasm, ${ }^{79}$ suggesting that Rab23 may have other unrevealed functions apart from membrane trafficking.

The ultimate effect of Hh signaling is activation of downstream Gli transcription factors, which regulate target genes by directly binding a consensus binding site (5'-tgggtggtc- $\left.3^{\prime}\right)$ in the promoter. ${ }^{13,14,80,81}$ The activity of Gli transcription factors can be regulated at several levels. First, nuclear-cytoplasmic shuttling of Gli molecules is tightly regulated. ${ }^{82-85}$ Protein kinase A can retain Glil protein in the cytoplasm via a protein kinase A site in the nuclear localization signal domain ${ }^{83}$ whereas activated Ras signaling induces Gli nuclear localization. ${ }^{85}$ Second, ubiquitination, acetylation, and protein degradation of Gli molecules are regulated by several distinct mechanisms, including $\beta$-TRCP-, cul3/BTB-, and numb/itch-mediated Gli ubiquitination, sumoylation, and acetylation ${ }^{86-93}$ In addition, Gli3 (Gli2 to a lesser extent) can be processed into transcriptional repressors, which may be mediated by the $\beta$-TRCP E3 ligase ${ }^{88,94} \mathrm{SuFu}$ not only prevents nuclear translocation of Gli molecules but also inhibits Gli1-mediated transcriptional activity ${ }^{95-97}$ Other mechanisms to modify Gli functions include interaction with a negative regulator sucrose nonfermenting $5(\mathrm{SNF} 5)^{98}$ and a positive regulator protein kinase $\mathrm{C}$ isoform $\mathrm{v} / \lambda .{ }^{99}$

Several feedback regulatory loops exist in this pathway to maintain a certain level of Hh signaling in a given cell. PTC, HIP, GAS1, neuropilins, and Gli1 are components, as well as the target genes of this pathway. PTC and HIP provide negative feedback regulation, whereas Gli1 and Nrp1/2 form positive regulatory loops. On the other hand, GAS1 is downregulated by the Hh pathway but is a positive regulator for Hh signaling. ${ }^{100}$ Alterations of these loops would lead to abnormal signaling of this pathway, such as inactivation of PTCH1 in BCCs.

\section{Activation of the Hh pathway in human cancer}

The initial link between Hh signaling and human cancers was made from the discovery that mutations of human PTCH1 are associated with a rare and hereditary form of $\mathrm{BCC}$, basal cell nevus syndrome (BCNS) (also Gorlin syndrome). ${ }^{101-103}$ Gorlin syndrome is a rare autosomal genetic disease with two 
distinct sets of phenotypes: an increased risk of developing cancers such as BCCs, medulloblastomas, rhabdomyosarcomas, and meningiomas, as well as developmental defects such as bifid ribs and ectopic calcification. ${ }^{104}$

Almost all BCCs and about $30 \%$ of medulloblastomas have activated Hh signaling via gene mutations in PTCH1, SMO, or other Hh pathway molecules. ${ }^{105-109}$ In addition, cancers associated with Gorlin syndrome, including rhabdomyosarcoma ${ }^{110,111}$ and meningiomas, ${ }^{112-114}$ are reported to have gene mutations in the Hh signaling pathway or elevated Hh target gene expression. Activated Hh signaling has been detected in a variety of human cancer types, either in the tumor or in the stroma. ${ }^{100,115-117}$

Genetically engineered mice with Ptch1 and Smo genes have generated more convincing evidence for the critical role of Hh signaling in cancer. In addition to BCCs and medulloblastomas, rhabdomyosarcomas develop in mice with expression of oncogenic SmoM2 or knockout of Ptch1. ${ }^{118-121}$ One surprising finding from tissue-specific Ptch1 knockout is the development of gastrointestinal stromal-like tumors (GIST), ${ }^{122}$ suggestive of a role of Hh signaling in GIST. Even in the situation of a small cell lung cancer (SCLC) mouse model, expression of oncogenic SmoM2 increases the tumor number, whereas $S m o$ knockout reduces the tumor number. ${ }^{123}$ Recent study of Barrett's esophagus indicates that sonic Hh expression in the epithelium of the esophagus can lead to stromal expression of Hh signaling target genes, which is similar to the human situation. ${ }^{124,125}$ In contrast, tissuespecific expression of oncogenic Smo molecule SmoM2 has no effects on K-Ras-induced pancreatic cancer ${ }^{126}$ or on prostate cancer. ${ }^{127}$ The negative data, however, do not rule out the promoting effects of Hh signaling for tumor metastasis, a major factor for cancer mortality. Currently, there are only a limited number of mouse models for cancer metastasis. Even for the available mouse models for cancer metastasis, several variable factors make cancer metastasis models less robust, and these factors include mouse genetic backgrounds, low incidence, and long duration to observe metastasis in mice.

\section{Hh signaling in tumor initiation, promotion, and metastases}

Hh signaling plays different roles in different types of cancer. ${ }^{100}$ Based on the published data, we attempt to divide the functions of $\mathrm{Hh}$ signaling during cancer development into three types: the tumor driver, the tumor promoter, or the regulator for residual cancer cells after therapy. For example, activated Hh signaling can drive development of BCCs, medulloblastomas, rhabdomyosarcoma, GIST, and Barrett's esophagus, ${ }^{118,119,122,124,128,129}$ and Hh signaling in these lesions serves as the tumor driver, at least in the mouse models. For SCLC, Hh signaling can promote cancer development but is not sufficient to drive tumor formation, and thus serves as a tumor promoter. ${ }^{123}$ In pancreatic cancer, inhibition of $\mathrm{Hh}$ signaling does not affect tumor formation but can promote tumor metastasis. ${ }^{130-137}$ For other cancer types, Hh signaling may regulate the number of cancer stem cells or the tumor microenvironment, such as leukemia and liver cancer. ${ }^{138,139}$ As more in vivo data are available, we predict more revelation of the tumor promoting role of Hh signaling. Tumor recurrence after therapy is a major issue in clinical care of cancer patients, such as chemotherapy or radiotherapy resistance, and will be discussed in "Hh signaling, cancer stem cell, and residual cancer cells." For some cancer types, Hh signaling may not have any roles to play.

Activation of Hh signaling does not work in isolation but rather crosstalks with other signaling pathways during cancer development and metastasis. Earlier studies indicated that $P t c h 1^{+/-}$mice with $P 53$ knock out all developed medulloblastomas, whereas $<30 \%$ of $P t c h 1^{+/-}$mice (with wild-type $P 53$ ) had this type of tumor. ${ }^{140}$ We have shown that skin-specific knockout of Stat3 or its upstream activator Il1 1ra significantly reduced Hh signaling-mediated BCC formation. ${ }^{141}$ Increasing data have indicated close collaboration between $\mathrm{Hh}$ signaling and growth factor signaling pathways. Our earlier work indicated that platelet-derived growth factor $\alpha$ (PDGFR $\alpha)$ is regulated by Hh signaling and is responsible for cell proliferation in BCCs. ${ }^{142}$ Now more links are reported between $\mathrm{Hh}$ and other pathways, including epidermal growth factor, insulin growth factor, transforming growth factor $\beta$ (TGF $\beta$ ), mTOR/S6K1, RACK1, notch, and protein kinase C. ${ }^{100,143-151}$ Although some of these molecules are involved in regulation of tumor microenvironment, such as TGF $\beta$, others are known to regulate cancer stem cells, such as PDGFR $\alpha$ and notch. We will have more discussion on cancer stem cells in "Hh signaling, cancer stem cell, and residual cancer cells."

Increasing evidence indicates that Hh signaling plays an important role during tumor metastasis in several types of cancer, such as pancreatic and breast cancers. ${ }^{135,152}$ Studies from many groups indicate activation of Hh signaling in the stromal as well as tumor compartments in metastatic pancreatic cancer. ${ }^{130,133-137,153}$ In fact, Hh signaling inhibitors are effective in suppressing tumor metastases of pancreatic cancer. ${ }^{135} \mathrm{Hh}$ signaling also regulates bone homeostasis as well as bone metastasis in breast cancer independent of 
the Hh ligands. ${ }^{143}$ During tumor metastasis, Hh signaling activation is observed both in the tumor compartment and in the stroma. ${ }^{135}$ The molecules mediating Hh's metastatic functions remain largely untested, but there are reports to indicate the following molecules: snail, TGF $\beta$, Wnt, HGF, and muc5 AC. ${ }^{135,154-157}$ Further studies will be needed to understand the molecular basis by which Hh signaling mediates cancer metastases.

\section{Hh signaling inhibitors: preclinical and clinical studies}

More than 200 compounds have been disclosed to have inhibitory effects on Hh signaling. Of these, eight have been used for clinical trials (see Table 1 for the list). There are three major targeting sites for Hh signaling inhibitors identified so far: Hh molecules (Shh neutralizing antibodies, small molecule Robotnikinin), SMO protein (cyclopamine and its derivatives IPI-926 and CycT, and synthetic compounds GDC-0449, XL-139/BMS833923, LDE-225, PF04449913, and LY2940680), and Gli inhibitors (HPI-1, HPI-2, GANT-56, and GANT-61). ${ }^{100}$ The major advances include successful clinical trials using GDC-0449 and US Food and Drug Administration approval of GDC-0449 for treatment of locally advanced and metastatic BCCs. However, combination of Hh signaling inhibitors with gemcitabine or $\mathrm{Hh}$ signaling inhibitors alone did not show any improvements in the outcomes of pancreatic cancer patients. We summarize these data below.

Table 1 shows the list of Hh signaling inhibitors in clinical trials, with all eight small molecules targeting SMO. Clinical trials with GDC-0449 in BCCs are the most successful. The successful Phase II clinical trials were preceded with a remarkable Phase I clinical trial in patients with metastatic BCCs. ${ }^{158}$ This drug is well tolerated by patients. ${ }^{159-161}$ Two independent groups used GDC-0449 to treat BCNS patients and sporadic BCCs, respectively, via oral administration.
Although the overall outcomes were very encouraging, the responses of two groups of patients were quite different. Although BCNS patients had virtually a $100 \%$ response rate, sporadic BCCs had only a 33\% response rate. Previous studies in mouse models indicate that tumors acquire somatic mutations in Smo or other signaling pathways following GDC-0449 administration, ${ }^{162}$ which may explain why not all sporadic BCCs responded well. A more rational way to treat sporadic BCCs is topical application. Two groups (one from Novartis AG and one from Hoffmann-La Roche Ltd/ Genentech) indeed tested that possibility with BCNS patients and obtained impressive responses. ${ }^{163,164}$ Mechanisms to Smo antagonist resistance include mutations in the target SMO gene or alterations in the PI3K pathway. ${ }^{165,166}$ Several ways have been explored to mitigate drug resistance to SMO antagonists, such as itraconazole and arsenic trioxide, polymeric nanoparticle-encapsulated Hh signaling inhibitors, or vitamin D3. ${ }^{167-170}$ Hopefully, some of these combined treatments will provide benefits to BCC patients.

Studies in animal models demonstrated significant inhibition of Hh signaling inhibitors on medulloblastoma development. For example, oral administration of IPI-926 or PF-5274857 can reduce tumor development, leading to a longer lifespan in mouse medulloblastoma models. ${ }^{171,172}$ However, an early clinical trial on a medulloblastoma patient using GDC-0449 yielded only a transient therapeutic effect, due to an $S M O$ mutation occurring soon after treatment. ${ }^{173}$ The outcome data of current medulloblastoma clinical trials are not available, but there is still a high expectation.

There is evidence to support that rhabdomyosarcoma is very responsive to $\mathrm{Hh}$ signaling inhibitors. First, gene expression analyses revealed elevated $\mathrm{Hh}$ target gene expression in embryonic rhabdomyosarcomas. ${ }^{111}$ Second, preliminary studies used forskolin or SMO inhibitor to shrink tumors in mouse models. ${ }^{174}$ In addition, evidence for Hh signaling in meningiomas and SCLC is quite clear, and

Table I A list of hedgehog signaling inhibitors in clinical trials (from http://clinicaltrials.gov) ${ }^{\mathrm{a}}$

\begin{tabular}{|c|c|c|c|c|c|}
\hline Molecule & Other names & Phase & Tumor types & FDA approval & Company \\
\hline GDC-0449 & Vismodegib/erivedge & $\mathrm{I} / \mathrm{II} / \mathrm{III}$ & BCCs and solid tumors & $\mathrm{BCCs}$ & Hoffmann-La Roche Ltd \\
\hline IPI-926 & & $\mathrm{I} / \mathrm{II}$ & Solid tumors & & Infinity Pharmaceuticals, Inc. \\
\hline LDE225 & & $\mathrm{I} / \mathrm{II}$ & Leukemia and solid tumors & & Novartis AG \\
\hline LEQ506 & & I & Solid tumors & & Novartis AG \\
\hline PF-044499I3 & & $\mathrm{I} / \mathrm{II}$ & Leukemia and solid tumors & & Pfizer, Inc. \\
\hline TAK-44I & & I & Solid tumors & & Millennium Pharmaceuticals, Inc. \\
\hline BMS833923 & $X L-139$ & $\mathrm{I} / \mathrm{II}$ & SCLC and solid tumors & & Bristol-Myers Squibb \\
\hline LY2940680 & & $\mathrm{I} / \mathrm{II}$ & SCLC/advanced cancer & & Eli Lilly and Company \\
\hline
\end{tabular}

Notes: aAll small molecules target smoothened molecule. GDC-0449 has been approved by the FDA to treat locally advanced and metastatic BCCs. There are no ongoing clinical trials for LEQ506, TAK-44I, and BMS833923.

Abbreviations: BCC, basal cell carcinoma; FDA, US Food and Drug Administration; SCLC, small cell lung cancer. 
Hh signaling inhibitors should be effective in these tumor types as well.

\section{Hh signaling, cancer stem cell, and residual cancer cells}

Increasing evidence indicates that $\mathrm{Hh}$ signaling is critical for cancer stem cell maintenance and function. ${ }^{138,175,176}$ For example, leukemia stem cell maintenance and expansion are dependent on Hh signaling. ${ }^{138,175}$ The effect of Hh signaling on a normal hematopoietic stem cell population, however, is still quite controversial, with some showing effects but others with no effects. ${ }^{138,177-180}$ Based on cancer stem cell theory, it is anticipated that $\mathrm{Hh}$ signaling activation exerts resistance to cancer chemotherapy and radiotherapy ${ }^{181}$ Several studies have indeed shown that Hh signaling activation is associated with chemotherapy or radiotherapy resistance. ${ }^{182-183}$ Hh signaling inhibitor IPI-926 enhances delivery of the chemotherapeutical drug gemcitabine in a mouse model of pancreatic cancer. Relevance to the cancer stem cell theory is the link between Hh signaling activation and cancer relapse from drug resistance.

Based on the published data, we propose that Hh signaling may help maintain the stemness of cancer stem cells, which are generally insensitive to chemotherapy and radiotherapy. There is evidence to indicate that $\mathrm{Hh}$ signaling regulates expression of cancer stem cell-related markers, such as aldehyde dehydrogenase, Bmi1, snail, Wnt2, PDGFR $\alpha$, jagged-1, CD44, and c-MET. ${ }^{135,155,184-188}$ The level of Hh expression is often higher in the cancer stem cell population in several cancer types. ${ }^{189-193}$ Thus, we have reasons to believe that inhibition of Hh signaling may be effective in reducing the number of cancer stem cells, which may play an important role in chemotherapy and radiotherapy resistance.

Chemotherapy and radiotherapy play an important role in the clinical care of cancer patients, but resistance to these treatments remains a major obstacle in cancer patient care. Recent studies revealed a few examples for the role of $\mathrm{Hh}$ signaling in chemotherapy and radiotherapy resistance. Resistance to docetaxel is a major clinical challenge for prostate cancer patients. A recent study revealed an important role of Hh signaling on docetaxel resistance in prostate cancer. ${ }^{194}$ Combination of notch and Hh signaling inhibitors was able to reverse docetaxel resistance both in cultured cells and in xenografts. Activation of Hh signaling via PI3 K is also reported in tamoxifen-resistant breast cancer, ${ }^{195}$ and a combination of Hh signaling inhibitor GDC-0449 with tamoxifen significantly reduced cell colony formation and tumor development in xenografts. In addition, activated $\mathrm{Hh}$ signaling is shown to be responsible for drug resistance in ovarian cancer, cervical cancer, and myeloid leukemic cells. ${ }^{196-198}$ A recent study also suggests that Hh signaling may be associated with antiepidermal growth factor receptor therapy (targeted therapy) resistance observed in head and neck cancer. ${ }^{144}$ The exact mechanisms by which Hh signaling activation confers drug resistance are not entirely clear, but it is reported that Hh signaling can regulate expression of several drug resistance-related genes such as ABCG2 and MDR. ${ }^{198,199}$ The cancer stem cell theory can also explain some of the mechanisms.

Overcoming recurrence to radiotherapy is also very challenging, but recent studies suggest that inhibiting Hh signaling may help mitigate radiotherapy resistance in pancreatic and head/neck cancer. For pancreatic cancer, we found that a combination of Hh signaling inhibitor BMS833932 (see Table 1 for details) and radiation could significantly reduce the number of lymph node metastasis. ${ }^{135}$ Similarly, high expression of Gli1 is reported to be associated with lymph node metastases and tumor progression after radiotherapy in squamous cell carcinomas of the head/neck. ${ }^{200}$

\section{Summary and future perspectives}

In summary, the link of Hh signaling activation to a variety of human cancer implies the relevance of studying Hh signaling to human health. Rapid advancement in the discovery of novel Hh signaling inhibitors has provided many opportunities for developing novel cancer therapeutic strategies. It is not surprising to learn that several major challenges still exist to prevent the use of Hh signaling inhibitors in clinics. These challenges include a lack of basic understanding of the molecular mechanisms by which Hh signaling mediates carcinogenesis; no clear criteria to identify the right tumors for therapeutic application; only a few reliable, physiologically relevant, and reproducible mouse models for cancer metastases to test and optimize drug dosages in order to minimize side effects; and a lack of clear strategies to mitigate drug resistance. Over the last 3 years, research in this area has greatly improved, as indicated in this review. It is anticipated that additional novel therapeutic strategies will be developed for cancer clinical trials using Hh signaling inhibitors in the next few years.

\section{Acknowledgment}

Current research in the authors' laboratory is supported by grants from the National Cancer Institute (CA94160, CA155086), Riley Children's Foundation, and Wells Center for Pediatric Research. Due to space limit, we could not 
include many important findings in this review but want to take this opportunity to thank all the investigators in this field for their work.

\section{Disclosure}

The authors report no conflicts of interest in this work.

\section{References}

1. Nusslein-Volhard C, Wieschaus E. Mutations affecting segment number and polarity in Drosophila. Nature. 1980;287(5785):795-801.

2. Krauss S, Concordet JP, Ingham PW. A functionally conserved homolog of the Drosophila segment polarity gene hh is expressed in tissues with polarizing activity in zebrafish embryos. Cell. 1993;75(7):1431-1444.

3. Echelard Y, Epstein DJ, St-Jacques B, et al. Sonic hedgehog, a member of a family of putative signaling molecules, is implicated in the regulation of CNS polarity. Cell. 1993;75(7):1417-1430.

4. Riddle RD, Johnson RL, Laufer E, Tabin C. Sonic hedgehog mediates the polarizing activity of the ZPA. Cell. 1993;75(7):1401-1416.

5. Chang DT, López A, von Kessler DP, et al. Products, genetic linkage and limb patterning activity of a murine hedgehog gene. Development. 1994;120(11):3339-3353.

6. Roelink H, Augsburger A, Heemskerk J, et al. Floor plate and motor neuron induction by vhh-1, a vertebrate homolog of hedgehog expressed by the notochord. Cell. 1994;76(4):761-775.

7. Epstein EH. Basal cell carcinomas: attack of the hedgehog. Nat Rev Cancer. 2008;8(10):743-754.

8. Xie J. Hedgehog signaling in prostate cancer. Future Oncol. 2005;1(3): 331-338

9. Xie J. Hedgehog signaling pathway: development of antagonists for cancer therapy. Curr Oncol Rep. 2008;10(2):107-113.

10. Xie J. Molecular biology of basal and squamous cell carcinomas. $A d v$ Exp Med Biol. 2008;624:241-251.

11. Jiang J, Hui CC. Hedgehog signaling in development and cancer. Dev Cell. 2008;15(6):801-812.

12. Ingham PW, Placzek M. Orchestrating ontogenesis: variations on a theme by sonic hedgehog. Nat Rev Genet. 2006;7(11):841-850

13. Sasaki $\mathrm{H}$, Hui C, Nakafuku M, Kondoh $\mathrm{H}$. A binding site for Gli proteins is essential for HNF-3beta floor plate enhancer activity in transgenics and can respond to Shh in vitro. Development. 1997;124(7):1313-1322.

14. Kinzler KW, Vogelstein B. The Gli gene encodes a nuclear protein which binds specific sequences in the human genome. Mol Cell Biol. 1990;10(2):634-642.

15. McMahon AP, Ingham PW, Tabin CJ. Developmental roles and clinical significance of hedgehog signaling. Curr Top Dev Biol. 2003;53:1-114.

16. Ingham PW, McMahon AP. Hedgehog signaling in animal development: paradigms and principles. Genes Dev. 2001;15(23):3059-3087.

17. Taipale J, Beachy PA. The hedgehog and Wnt signalling pathways in cancer. Nature. 2001;411(6835):349-354.

18. Lee JJ, Ekker SC, von Kessler DP, Porter JA, Sun BI, Beachy PA Autoproteolysis in hedgehog protein biogenesis. Science. 1994; 266(5190):1528-1537.

19. Porter JA, Young KE, Beachy PA. Cholesterol modification of hedgehog signaling proteins in animal development. Science. 1996;274(5285):255-259.

20. Porter JA, von Kessler DP, Ekker SC, et al. The product of hedgehog autoproteolytic cleavage active in local and long-range signalling. Nature. 1995;374(6520):363-366.

21. Buglino JA, Resh MD. Hhat is a palmitoylacyltransferase with specificity for N-palmitoylation of sonic hedgehog. $J$ Biol Chem. 2008;283(32):22076-22088.

22. Kawakami T, Kawcak T, Li YJ, Zhang W, Hu Y, Chuang PT. Mouse dispatched mutants fail to distribute hedgehog proteins and are defective in hedgehog signaling. Development. 2002;129(24):5753-5765.
23. Ma Y, Erkner A, Gong R, et al. Hedgehog-mediated patterning of the mammalian embryo requires transporter-like function of dispatched. Cell. 2002;111(1):63-75.

24. Caspary T, García-García MJ, Huangfu D, et al. Mouse dispatched homolog 1 is required for long-range, but not juxtacrine, Hh signaling. Curr Biol. 2002;12(18):1628-1632.

25. Dierker T, Dreier R, Petersen A, Bordych C, Grobe K. Heparan sulfatemodulated, metalloprotease-mediated sonic hedgehog release from producing cells. J Biol Chem. 2009;284(12):8013-8022.

26. Beckett K, Franch-Marro X, Vincent JP. Glypican-mediated endocytosis of hedgehog has opposite effects in flies and mice. Trends Cell Biol. 2008;18(8):360-363.

27. Lum L, Yao S, Mozer B, et al. Identification of hedgehog pathway components by RNAi in Drosophila cultured cells. Science. 2003;299(5615):2039-2045.

28. Baena-Lopez LA, Rodriguez I, Baonza A. The tumor suppressor genes dachsous and fat modulate different signalling pathways by regulating dally and dally-like. Proc Natl Acad Sci U S A. 2008;105(28): 9645-9650.

29. Toyoda H, Kinoshita-Toyoda A, Fox B, Selleck SB. Structural analysis of glycosaminoglycans in animals bearing mutations in sugarless, sulfateless, and tout-velu. Drosophila homologues of vertebrate genes encoding glycosaminoglycan biosynthetic enzymes. $J$ Biol Chem. 2000;275(29):21856-21861.

30. Bellaiche Y, The I, Perrimon N. Tout-velu is a Drosophila homologue of the putative tumour suppressor EXT-1 and is needed for Hh diffusion. Nature. 1998;394(6688):85-88.

31. Koziel L, Kunath M, Kelly OG, Vortkamp A. Ext1-dependent heparan sulfate regulates the range of Ihh signaling during endochondral ossification. Dev Cell. 2004;6(6):801-813.

32. Stone DM, Hynes M, Armanini M, et al. The tumour-suppressor gene patched encodes a candidate receptor for sonic hedgehog. Nature. 1996;384(6605):129-134.

33. Taipale J, Cooper MK, Maiti T, Beachy PA. Patched acts catalytically to suppress the activity of smoothened. Nature. 2002;418(6900): 892-897.

34. Chuang PT, McMahon AP. Vertebrate hedgehog signalling modulated by induction of a hedgehog-binding protein. Nature. 1999;397(6720): 617-621.

35. Martinelli DC, Fan CM. Gas1 extends the range of hedgehog action by facilitating its signaling. Genes Dev. 2007;21(10):1231-1243.

36. Seppala M, Depew MJ, Martinelli DC, Fan CM, Sharpe PT, Cobourne MT. Gas 1 is a modifier for holoprosencephaly and genetically interacts with sonic hedgehog. J Clin Invest. 2007;117(6): $1575-1584$.

37. Allen BL, Tenzen T, McMahon AP. The hedgehog-binding proteins Gas1 and Cdo cooperate to positively regulate Shh signaling during mouse development. Genes Dev. 2007;21(10):1244-1257.

38. Okada A, Charron F, Morin S, et al. Boc is a receptor for sonic hedgehog in the guidance of commissural axons. Nature. 2006;444(7117): 369-373.

39. Tenzen T, Allen BL, Cole F, Kang JS, Krauss RS, McMahon AP. The cell surface membrane proteins $\mathrm{Cdo}$ and Boc are components and targets of the hedgehog signaling pathway and feedback network in mice. Dev Cell. 2006;10(5):647-656.

40. Zhang W, Kang JS, Cole F, Yi MJ, Krauss RS. Cdo functions at multiple points in the sonic hedgehog pathway, and Cdo-deficient mice accurately model human holoprosencephaly. Dev Cell. 2006;10(5): $657-665$.

41. Yao S, Lum L, Beachy P. The ihog cell-surface proteins bind hedgehog and mediate pathway activation. Cell. 2006;125(2):343-357.

42. Capurro MI, Xu P, Shi W, Li F, Jia A, Filmus J. Glypican-3 inhibits hedgehog signaling during development by competing with patched for hedgehog binding. Dev Cell. 2008;14(5):700-711.

43. Li F, Shi W, Capurro M, Filmus J. Glypican-5 stimulates rhabdomyosarcoma cell proliferation by activating hedgehog signaling. J Cell Biol. 2011;192(4):691-704. 
44. Witt RM, Hecht ML, Pazyra-Murphy MF, et al. Heparan sulfate proteoglycans containing a glypican 5 core and 2-O-sulfo-iduronic acid function as sonic hedgehog co-receptors to promote proliferation. J Biol Chem. 2013;288(36):26275-26288.

45. Sanchez-Hernandez D, Sierra J, Ortigao-Farias JR, Guerrero I. The WIF domain of the human and Drosophila Wif-1 secreted factors confers specificity for Wnt or hedgehog. Development. 2012;139(20): 3849-3858.

46. Avanesov A, Honeyager SM, Malicki J, Blair SS. The role of glypicans in Wnt inhibitory factor-1 activity and the structural basis of Wifl's effects on Wnt and hedgehog signaling. PLoS Genetics. 2012;8(2):e1002503.

47. Yavari A, Nagaraj R, Owusu-Ansah E, et al. Role of lipid metabolism in smoothened derepression in hedgehog signaling. Dev Cell. 2010;19(1):54-65.

48. Khaliullina H, Panakova D, Eugster C, Riedel F, Carvalho M, Eaton S. Patched regulates smoothened trafficking using lipoprotein-derived lipids. Development. 2009;136(24):4111-4121.

49. Callejo A, Culi J, Guerrero I. Patched, the receptor of hedgehog, is a lipoprotein receptor. Proc Natl Acad Sci U S A. 2008;105(3):912-917.

50. Bijlsma MF, Spek CA, Zivkovic D, van de Water S, Rezaee F, Peppelenbosch MP. Repression of smoothened by patched-dependent (pro-)vitamin D3 secretion. PLoS Biol. 2006;4(8):e232.

51. Wang Y, Davidow L, Arvanites AC, et al. Glucocorticoid compounds modify smoothened localization and hedgehog pathway activity. Chem Bio. 2012;19(8):972-982.

52. Philipp M, Fralish GB, Meloni AR, et al. Smoothened signaling in vertebrates is facilitated by a $\mathrm{G}$ protein-coupled receptor kinase. $\mathrm{Mol}$ Biol Cell. 2008;19(12):5478-5489.

53. Ogden SK, Fei DL, Schilling NS, Ahmed YF, Hwa J, Robbins DJ. $\mathrm{G}$ protein Galphai functions immediately downstream of smoothened in hedgehog signalling. Nature. 2008;456(7224):967-970.

54. Molnar C, Holguin H, Mayor F Jr, Ruiz-Gomez A, de Celis JF. The $\mathrm{G}$ protein-coupled receptor regulatory kinase GPRK2 participates in hedgehog signaling in Drosophila. Proc Natl Acad Sci U S A. 2007;104(19):7963-7968.

55. Riobo NA, Saucy B, Dilizio C, Manning DR. Activation of heterotrimeric G proteins by smoothened. Proc Natl Acad Sci U S A. 2006;103(33):12607-12612.

56. Douglas AE, Heim JA, Shen F, et al. The alpha subunit of the G protein G13 regulates activity of one or more Gli transcription factors independently of smoothened. J Biol Chem. 2011;286(35):30714-30722.

57. Zhao Y, Tong C, Jiang J. Hedgehog regulates smoothened activity by inducing a conformational switch. Nature. 2007;450(7167):252-258.

58. Corbit KC, Aanstad P, Singla V, Norman AR, Stainier DY, Reiter JF. Vertebrate smoothened functions at the primary cilium. Nature. 2005;437(7061):1018-1021.

59. Huangfu D, Liu A, Rakeman AS, Murcia NS, Niswander L, Anderson KV. Hedgehog signalling in the mouse requires intraflagellar transport proteins. Nature. 2003;426(6962):83-87.

60. May SR, Ashique AM, Karlen M, et al. Loss of the retrograde motor for IFT disrupts localization of Smo to cilia and prevents the expression of both activator and repressor functions of Gli. Dev Biol. 2005;287(2):378-389.

61. Huangfu D, Anderson KV. Cilia and hedgehog responsiveness in the mouse. Proc Natl Acad Sci U S A. 2005;102(32):11325-11330.

62. Zhang Q, Davenport JR, Croyle MJ, Haycraft CJ, Yoder BK. Disruption of IFT results in both exocrine and endocrine abnormalities in the pancreas of Tg737(orpk) mutant mice. Lab Invest. 2005;85(1): $45-64$.

63. Hoover AN, Wynkoop A, Zeng H, Jia J, Niswander LA, Liu A. C2cd3 is required for cilia formation and hedgehog signaling in mouse. Development. 2008;135(24):4049-4058.

64. Hillman RT, Feng BY, Ni J, et al. Neuropilins are positive regulators of hedgehog signal transduction. Genes Dev. 2011;25(22):2333-2346.

65. Snuderl M, Batista A, Kirkpatrick ND, et al. Targeting placental growth factor/neuropilin 1 pathway inhibits growth and spread of medulloblastoma. Cell. 2013;152(5):1065-1076.
66. Cao Y, Wang L, Nandy D, et al. Neuropilin-1 upholds dedifferentiation and propagation phenotypes of renal cell carcinoma cells by activating Akt and sonic hedgehog axes. Cancer Res. 2008;68(21): 8667-8672.

67. Parra LM, Zou Y. Sonic hedgehog induces response of commissural axons to Semaphorin repulsion during midline crossing. Nat Neurosci. 2010;13(1):29-35.

68. Cheung HO, Zhang X, Ribeiro A, et al. The kinesin protein Kif7 is a critical regulator of Gli transcription factors in mammalian hedgehog signaling. Sci Signal. 2009;2(76):ra29.

69. Endoh-Yamagami S, Evangelista M, Wilson D, et al. The mammalian Cos 2 homolog Kif7 plays an essential role in modulating Hh signal transduction during development. Curr Biol. 2009;19(15):1320-1326.

70. Law KK, Makino S, Mo R, Zhang X, Puviindran V, Hui CC. Antagonistic and cooperative actions of Kif7 and Sufu define graded intracellular Gli activities in hedgehog signaling. PLoS One. 2012;7(11):e50193.

71. Li ZJ, Nieuwenhuis E, Nien W, et al. Kif7 regulates Gli2 through Sufu-dependent and -independent functions during skin development and tumorigenesis. Development. 2012;139(22):4152-4161.

72. Hsu SH, Zhang X, Yu C, et al. Kif7 promotes hedgehog signaling in growth plate chondrocytes by restricting the inhibitory function of Sufu. Development. 2011;138(17):3791-3801.

73. Wilson CW, Nguyen CT, Chen MH, et al. Fused has evolved divergent roles in vertebrate hedgehog signalling and motile ciliogenesis. Nature. 2009;459(7243):98-102.

74. Merchant M, Evangelista M, Luoh SM, et al. Loss of the serine/threonine kinase fused results in postnatal growth defects and lethality due to progressive hydrocephalus. Mol Cell Biol. 2005;25(16):7054-7068.

75. Chen MH, Gao N, Kawakami T, Chuang PT. Mice deficient in the fused homolog do not exhibit phenotypes indicative of perturbed hedgehog signaling during embryonic development. Mol Cell Biol. 2005;25(16): 7042-7053.

76. Eggenschwiler JT, Espinoza E, Anderson KV. Rab23 is an essential negative regulator of the mouse sonic hedgehog signalling pathway. Nature. 2001;412(6843):194-198.

77. Reiter JF, Skarnes WC. Tectonic, a novel regulator of the hedgehog pathway required for both activation and inhibition. Genes Dev. 2006;20(1):22-27.

78. Li C, Chi S, Xie J. Hedgehog signaling in skin cancers. Cell Signal. 2011;23(8):1235-1243.

79. Huang S, Yang L, An Y, et al. Expression of hedgehog signaling molecules in lung cancer. Acta Histochem. 2011;113(5):564-569.

80. Kinzler KW, Ruppert JM, Bigner SH, Vogelstein B. The Gli gene is a member of the Kruppel family of zinc finger proteins. Nature. 1988;332(6162):371-374.

81. Ruppert JM, Kinzler KW, Wong AJ, et al. The Gli-Kruppel family of human genes. Mol Cell Biol. 1988;8(8):3104-3113.

82. Barnfield PC, Zhang X, Thanabalasingham V, Yoshida M, Hui CC. Negative regulation of Gli1 and Gli2 activator function by suppressor of fused through multiple mechanisms. Differentiation. 2005;73(8): 397-405.

83. Sheng T, Chi S, Zhang X, Xie J. Regulation of Gli1 localization by the $\mathrm{cAMP} /$ protein kinase A signaling axis through a site near the nuclear localization signal. J Biol Chem. 2006;281(1):9-12.

84. Kogerman P, Grimm T, Kogerman L, et al. Mammalian suppressor-offused modulates nuclear-cytoplasmic shuttling of Gli-1. Nat Cell Biol. 1999;1(5):312-319.

85. Stecca B, Mas C, Clement V, et al. Melanomas require hedghog-Gli signaling regulated by interactions between Glil and the RASMEK/AKT pathways. Proc Natl Acad Sci U S A. 2007;104(14): 5895-5900.

86. Pan Y, Bai CB, Joyner AL, Wang B. Sonic hedgehog signaling regulates Gli2 transcriptional activity by suppressing its processing and degradation. Mol Cell Biol. 2006;26(9):3365-3377.

87. Huntzicker EG, Estay IS, Zhen H, Lokteva LA, Jackson PK, Oro AE. Dual degradation signals control Gli protein stability and tumor formation. Genes Dev. 2006;20(3):276-281. 
88. Wang B, Li Y. Evidence for the direct involvement of $\beta \operatorname{TrCP}$ in Gli3 protein processing. Proc Natl Acad Sci U S A. 2006;103(1):33-38.

89. Di Marcotullio L, Ferretti E, Greco A, et al. Numb is a suppressor of hedgehog signalling and targets Gli1 for Itch-dependent ubiquitination. Nat Cell Biol. 2006;8(12):1415-1423.

90. Jiang J. Regulation of $\mathrm{Hh} / \mathrm{Gli}$ signaling by dual ubiquitin pathways. Cell Cycle. 2006;5(21):2457-2463.

91. Canettieri G, Di Marcotullio L, Greco A, et al. Histone deacetylase and Cullin3-REN(KCTD11) ubiquitin ligase interplay regulates hedgehog signalling through Gli acetylation. Nat Cell Biol. 2010;12(2): 132-142.

92. Coni S, Antonucci L, D'Amico D, et al. Gli2 acetylation at lysine 757 regulates hedgehog-dependent transcriptional output by preventing its promoter occupancy. PLoS One. 2013;8(6):e65718.

93. Han L, Pan Y, Wang B. Small ubiquitin-like modifier (SUMO) modification inhibits Gli2 protein transcriptional activity in vitro and in vivo. J Biol Chem. 2012;287(24):20483-20489.

94. Zhang Q, Shi Q, Chen Y, et al. Multiple Ser/Thr-rich degrons mediate the degradation of Ci/Gli by the Cul3-HIB/SPOP E3 ubiquitin ligase. Proc Natl Acad Sci U S A. 2009;106(50):21191-21196.

95. Cheng SY, Bishop JM. Suppressor of fused represses Gli-mediated transcription by recruiting the SAP18-mSin 3 corepressor complex. Proc Natl Acad Sci U S A. 2002;99(8):5442-5447.

96. Wang C, Pan Y, Wang B. Suppressor of fused and Spop regulate the stability, processing and function of Gli2 and Gli3 full-length activators but not their repressors. Development. 2010;137(12):2001-2009.

97. Li ZJ, Mack SC, Mak TH, Angers S, Taylor MD, Hui CC. Evasion of p53 and G/M checkpoints are characteristic of Hh-driven basal cell carcinoma. Oncogene. Epub June 10, 2013.

98. Jagani Z, Mora-Blanco EL, Sansam CG, et al. Loss of the tumor suppressor Snf5 leads to aberrant activation of the hedgehog-Gli pathway. Nat Med. 2010;16(12):1429-1433.

99. Atwood SX, Li M, Lee A, Tang JY, Oro AE. Gli activation by atypical protein kinase $\mathrm{C}$ iota/lambda regulates the growth of basal cell carcinomas. Nature. 2013;494(7438):484-488.

100. Yang L, Xie G, Fan Q, Xie J. Activation of the hedgehog-signaling pathway in human cancer and the clinical implications. Oncogene. 2010;29(4):469-481.

101. Hahn H, Wicking C, Zaphiropoulous PG, et al. Mutations of the human homolog of Drosophila patched in the nevoid basal cell carcinoma syndrome. Cell. 1996;85(6):841-851.

102. Johnson RL, Rothman AL, Xie J, et al. Human homolog of patched, a candidate gene for the basal cell nevus syndrome. Science. 1996;272(5268):1668-1671.

103. Epstein E Jr. Genetic determinants of basal cell carcinoma risk. Med Pediatr Oncol. 2001;36(5):555-558.

104. Gorlin RJ. Nevoid basal-cell carcinoma syndrome. Medicine. 1987; 66(2):98-113.

105. Xie J, Murone M, Luoh SM, et al. Activating smoothened mutations in sporadic basal-cell carcinoma. Nature. 1998;391(6662):90-92.

106. Lam CW, Xie J, To KF, et al. A frequent activated smoothened mutation in sporadic basal cell carcinomas. Oncogene. 1999;18(3):833-836.

107. Reifenberger J, Wolter M, Knobbe CB, et al. Somatic mutations in the PTCH, SMOH, SUFUH and TP53 genes in sporadic basal cell carcinomas. Br J Dermatol. 2005;152(1):43-51.

108. Reifenberger J, Wolter M, Weber RG, et al. Missense mutations in $\mathrm{SMOH}$ in sporadic basal cell carcinomas of the skin and primitive neuroectodermal tumors of the central nervous system. Cancer Res. 1998;58(9):1798-1803.

109. Couve-Privat S, Bouadjar B, Avril MF, Sarasin A, Daya-Grosjean L. Significantly high levels of ultraviolet-specific mutations in the smoothened gene in basal cell carcinomas from DNA repair-deficient xeroderma pigmentosum patients. Cancer Res. 2002;62(24):7186-7189.

110. Tostar U, Malm CJ, Meis-Kindblom JM, Kindblom LG, Toftgard R, Unden AB. Deregulation of the hedgehog signalling pathway: a possible role for the PTCH and SUFU genes in human rhabdomyoma and rhabdomyosarcoma development. J Pathol. 2006;208(1):17-25.
111. Pressey JG, Anderson JR, Crossman DK, Lynch JC, Barr FG. Hedgehog pathway activity in pediatric embryonal rhabdomyosarcoma and undifferentiated sarcoma: a report from the Children's Oncology Group. Pediatr Blood Cancer. 2011;57(6):930-938.

112. Clark VE, Erson-Omay EZ, Serin A, et al. Genomic analysis of nonNF2 meningiomas reveals mutations in TRAF7, KLF4, AKT1, and SMO. Science. 2013;339(6123):1077-1080.

113. Aavikko M, Li SP, Saarinen S, et al. Loss of SUFU function in familial multiple meningioma. Am J Hum Genet. 2012;91(3):520-526.

114. Kijima C, Miyashita T, Suzuki M, Oka H, Fujii K. Two cases of nevoid basal cell carcinoma syndrome associated with meningioma caused by a PTCH1 or SUFU germline mutation. Fam Cancer. 2012;11(4): 565-570.

115. Fei DL, Sanchez-Mejias A, Wang Z, et al. Hedgehog signaling regulates bladder cancer growth and tumorigenicity. Cancer Res. 2012;72(17):4449-4458.

116. Rodriguez-Blanco J, Schilling NS, Tokhunts R, et al. The hedgehog processing pathway is required for NSCLC growth and survival. Oncogene. 2013;32(18):2335-2345.

117. Shin K, Lee J, Guo N, et al. Hedgehog/Wnt feedback supports regenerative proliferation of epithelial stem cells in bladder. Nature. 2011;472(7341):110-114.

118. Hahn H, Wojnowski L, Zimmer AM, Hall J, Miller G, Zimmer A. Rhabdomyosarcomas and radiation hypersensitivity in a mouse model of Gorlin syndrome. Nat Med. 1998;4(5):619-622.

119. Hatley ME, Tang W, Garcia MR, et al. A mouse model of rhabdomyosarcoma originating from the adipocyte lineage. Cancer Cell. 2012;22(4):536-546.

120. Ignatius MS, Chen E, Elpek NM, et al. In vivo imaging of tumorpropagating cells, regional tumor heterogeneity, and dynamic cell movements in embryonal rhabdomyosarcoma. Cancer Cell. 2012;21(5):680-693.

121. Nitzki F, Zibat A, Frommhold A, et al. Uncommitted precursor cells might contribute to increased incidence of embryonal rhabdomyosarcoma in heterozygous patched1-mutant mice. Oncogene. 2011;30(43):4428-4436.

122. Pelczar P, Zibat A, van Dop WA, et al. Inactivation of patched 1 in mice leads to development of gastrointestinal stromal-like tumors that express PDGFR $\alpha$ but not kit. Gastroenterology. 2013;144(1):134-144.

123. Park KS, Martelotto LG, Peifer M, et al. A crucial requirement for hedgehog signaling in small cell lung cancer. Nat Med. 2011;17(11): 1504-1508.

124. Wang DH, Clemons NJ, Miyashita T, et al. Aberrant epithelialmesenchymal hedgehog signaling characterizes Barrett's metaplasia. Gastroenterology. 2010;138(5):1810-1822.

125. Yang L, Wang LS, Chen XL, et al. Hedgehog signaling activation in the development of squamous cell carcinoma and adenocarcinoma of esophagus. Int J Biochem Mol Biol. 2012;3(1):46-57.

126. Tian H, Callahan CA, DuPree KJ, et al. Hedgehog signaling is restricted to the stromal compartment during pancreatic carcinogenesis. Proc Natl Acad Sci U S A. 2009;106(11):4254-4259.

127. Mao J, Ligon KL, Rakhlin EY, et al. A novel somatic mouse model to survey tumorigenic potential applied to the hedgehog pathway. Cancer Res. 2006;66(20):10171-10178.

128. Aszterbaum M, Epstein J, Oro A, et al. Ultraviolet and ionizing radiation enhance the growth of BCCs and trichoblastomas in patched heterozygous knockout mice. Nat Med. 1999;5(11):1285-1291.

129. Goodrich LV, Milenkovic L, Higgins KM, Scott MP. Altered neural cell fates and medulloblastoma in mouse patched mutants. Science. 1997;277(5329):1109-1113.

130. Feldmann G, Dhara S, Fendrich V, et al. Blockade of hedgehog signaling inhibits pancreatic cancer invasion and metastases: a new paradigm for combination therapy in solid cancers. Cancer Res. 2007;67(5): 2187-2196.

131. Bailey JM, Swanson BJ, Hamada T, et al. Sonic hedgehog promotes desmoplasia in pancreatic cancer. Clin Cancer Res. 2008;14(19): 5995-6004. 
132. Chang Q, Foltz WD, Chaudary N, Hill RP, Hedley DW. Tumor-stroma interaction in orthotopic primary pancreatic cancer xenografts during hedgehog pathway inhibition. Int J Cancer. 2013;133(1):225-234.

133. Tang SN, Fu J, Nall D, Rodova M, Shankar S, Srivastava RK. Inhibition of sonic hedgehog pathway and pluripotency maintaining factors regulate human pancreatic cancer stem cell characteristics. Int J Cancer. 2012;131(1):30-40.

134. Feldmann G, Fendrich V, McGovern K, et al. An orally bioavailable small-molecule inhibitor of hedgehog signaling inhibits tumor initiation and metastasis in pancreatic cancer. Mol Cancer Ther. 2008;7(9): $2725-2735$.

135. Gu D, Liu H, Su GH, et al. Combining hedgehog signaling inhibition with focal irradiation on reduction of pancreatic cancer metastasis. Mol Cancer Ther. 2013;12(6):1038-1048.

136. Bailey JM, Mohr AM, Hollingsworth MA. Sonic hedgehog paracrine signaling regulates metastasis and lymphangiogenesis in pancreatic cancer. Oncogene. 2009;28(40):3513-3525.

137. Olive KP, Jacobetz MA, Davidson CJ, et al. Inhibition of hedgehog signaling enhances delivery of chemotherapy in a mouse model of pancreatic cancer. Science. 2009;324(5933):1457-1461.

138. Zhao C, Chen A, Jamieson $\mathrm{CH}$, et al. Hedgehog signalling is essential for maintenance of cancer stem cells in myeloid leukaemia. Nature. 2009;458(7239):776-779.

139. Boyd AL, Salci KR, Shapovalova Z, McIntyre BA, Bhatia M. Nonhematopoietic cells represent a more rational target of in vivo hedgehog signaling affecting normal or acute myeloid leukemia progenitors. Exp Hematol. Epub June 6, 2013.

140. Romer JT, Kimura H, Magdaleno S, et al. Suppression of the Shh pathway using a small molecule inhibitor eliminates medulloblastoma in Ptc1(+/-)p53(-/-) mice. Cancer Cell. 2004;6(3):229-240.

141. Gu D, Fan Q, Zhang X, Xie J. A role for transcription factor STAT3 signaling in oncogene smoothened-driven carcinogenesis. J Biol Chem. 2012;287(45):38356-38366.

142. Xie J, Aszterbaum M, Zhang X, et al. A role of PDGFRalpha in basal cell carcinoma proliferation. Proc Natl Acad Sci USA. 2001;98(16):9255-9259.

143. Johnson RW, Nguyen MP, Padalecki SS, et al. TGF-beta promotion of Gli2-induced expression of parathyroid hormone-related protein, an important osteolytic factor in bone metastasis, is independent of canonical hedgehog signaling. Cancer Res. 2011;71(3):822-831.

144. Keysar SB, Le PN, Anderson RT, et al. Hedgehog signaling alters reliance on EGF receptor signaling and mediates anti-EGFR therapeutic resistance in head and neck cancer. Cancer Res. 2013;73(11): 3381-3392.

145. Eberl M, Klingler S, Mangelberger D, et al. Hedgehog-EGFR cooperation response genes determine the oncogenic phenotype of basal cell carcinoma and tumour-initiating pancreatic cancer cells. EMBO Mol Med. 2012;4(3):218-233.

146. Fan Q, He M, Sheng T, et al. Requirement of TGFbeta signaling for SMOmediated carcinogenesis. J Biol Chem. 2010;285(47):36570-36576.

147. Wang Y, Ding Q, Yen CJ, et al. The crosstalk of mTOR/S6K1 and hedgehog pathways. Cancer Cell. 2012;21(3):374-387.

148. Shi S, Deng YZ, Zhao JS, et al. RACK1 promotes non-small-cell lung cancer tumorigenicity through activating sonic hedgehog signaling pathway. J Biol Chem. 2012;287(11):7845-7858.

149. Hsieh A, Ellsworth R, Hsieh D. Hedgehog/Gli1 regulates IGF dependent malignant behaviors in glioma stem cells. J Cell Physiol. 2011;226(4):1118-1127.

150. Mainwaring LA, Kenney AM. Divergent functions for eIF4E and S6 kinase by sonic hedgehog mitogenic signaling in the developing cerebellum. Oncogene. 2011;30(15):1784-1797.

151. Fernandez LA, Squatrito M, Northcott P, et al. Oncogenic YAP promotes radioresistance and genomic instability in medulloblastoma through IGF2-mediated Akt activation. Oncogene. 2012;31(15):1923-1937.

152. Heller E, Hurchla MA, Xiang J, et al. Hedgehog signaling inhibition blocks growth of resistant tumors through effects on tumor microenvironment. Cancer Res. 2012;72(4):897-907.
153. Abbruzzese JL, National Institutes of Health (US). Are there new targets for pancreatic cancer therapeutics?; 2007. Available from: http:// videocast.nih.gov/launch.asp?13834. Accessed September 10, 2013.

154. Inaguma S, Kasai K, Ikeda H. Gli1 facilitates the migration and invasion of pancreatic cancer cells through MUC5AC-mediated attenuation of E-cadherin. Oncogene. 2011;30(6):714-723.

155. Joost S, Almada LL, Rohnalter V, et al. Glil inhibition promotes epithelial-to-mesenchymal transition in pancreatic cancer cells. Cancer Res. 2012;72(1):88-99.

156. Li X, Deng W, Lobo-Ruppert SM, Ruppert JM. Gli1 acts through snail and E-cadherin to promote nuclear signaling by beta-catenin. Oncogene. 2007;26(31):4489-4498.

157. Javelaud D, Pierrat MJ, Mauviel A. Crosstalk between TGF-beta and hedgehog signaling in cancer. FEBS Lett. 2012;586(14):2016-2025.

158. Von Hoff DD, LoRusso PM, Rudin CM, et al. Inhibition of the hedgehog pathway in advanced basal-cell carcinoma. N Engl J Med. September 17, 2009;361(12):1164-1172.

159. Graham RA, Lum BL, Cheeti S, et al. Pharmacokinetics of hedgehog pathway inhibitor vismodegib (GDC-0449) in patients with locally advanced or metastatic solid tumors: the role of alpha-1-acid glycoprotein binding. Clin Cancer Res. 2011;17(8):2512-2520.

160. LoRusso PM, Rudin CM, Reddy JC, et al. Phase I trial of hedgehog pathway inhibitor vismodegib (GDC-0449) in patients with refractory, locally advanced or metastatic solid tumors. Clin Cancer Res. 2011;17(8):2502-2511.

161. Lorusso PM, Jimeno A, Dy G, et al. Pharmacokinetic dose-scheduling study of hedgehog pathway inhibitor vismodegib (GDC-0449) in patients with locally advanced or metastatic solid tumors. Clin Cancer Res. 2011;17(17):5774-5782.

162. Metcalfe C, de Sauvage FJ. Hedgehog fights back: mechanisms of acquired resistance against smoothened antagonists. Cancer Res. 2011;71(15):5057-5061

163. Tang T, Tang JY, Li D, et al. Targeting superficial or nodular basal cell carcinoma with topically formulated small molecule inhibitor of smoothened. Clin Cancer Res. 2011;17(10):3378-3387.

164. Skvara H, Kalthoff F, Meingassner JG, et al. Topical treatment of basal cell carcinomas in nevoid basal cell carcinoma syndrome with a smoothened inhibitor. J Invest Dermatol. 2011;131(8): 1735-1744.

165. Buonamici S, Williams J, Morrissey M, et al. Interfering with resistance to smoothened antagonists by inhibition of the PI3K pathway in medulloblastoma. Sci Transl Med. 2010;2(51):51 ra70.

166. Dijkgraaf GJ, Alicke B, Weinmann L, et al. Small molecule inhibition of GDC-0449 refractory smoothened mutants and downstream mechanisms of drug resistance. Cancer Res. 2011;71(2): 435-444.

167. Kim J, Aftab BT, Tang JY, et al. Itraconazole and arsenic trioxide inhibit hedgehog pathway activation and tumor growth associated with acquired resistance to smoothened antagonists. Cancer Cell. 2013;23(1):23-34.

168. Kim J, Tang JY, Gong R, et al. Itraconazole, a commonly used antifungal that inhibits hedgehog pathway activity and cancer growth. Cancer Cell. 2010;17(4):388-399.

169. Tang JY, Xiao TZ, Oda Y, et al. Vitamin D3 inhibits hedgehog signaling and proliferation in murine basal cell carcinomas. Cancer Prev Res (Phila). 2011;4(5):744-751.

170. Chenna V, Hu C, Pramanik D, et al. A polymeric nanoparticle encapsulated small-molecule inhibitor of hedgehog signaling (NanoHHI) bypasses secondary mutational resistance to smoothened antagonists. Mol Cancer Ther. 2012;11(1):165-173.

171. Rohner A, Spilker ME, Lam JL, et al. Effective targeting of hedgehog signaling in a medulloblastoma model with PF-5274857, a potent and selective smoothened antagonist that penetrates the blood-brain barrier. Mol Cancer Ther. 2012;11(1):57-65.

172. Lee MJ, Hatton BA, Villavicencio EH, et al. Hedgehog pathway inhibitor saridegib (IPI-926) increases lifespan in a mouse medulloblastoma model. Proc Natl Acad Sci U S A. 2012;109(20):7859-7864. 
173. Rudin CM, Hann CL, Laterra J, et al. Treatment of medulloblastoma with hedgehog pathway inhibitor GDC-0449. $N$ Engl J Med. 2009;361(12):1173-1178.

174. Fulda S. Molecular targeted therapies for rhabdomyosarcoma: focus on hedgehog and apoptosis signaling. Klinische Padiatrie. 2013;225(3): 115-119.

175. Dierks C, Beigi R, Guo GR, et al. Expansion of Bcr-Abl-positive leukemic stem cells is dependent on hedgehog pathway activation. Cancer Cell. 2008;14(3):238-249.

176. Read TA, Fogarty MP, Markant SL, et al. Identification of CD15 as a marker for tumor-propagating cells in a mouse model of medulloblastoma. Cancer Cell. 2009;15(2):135-147.

177. Hofmann I, Stover EH, Cullen DE, et al. Hedgehog signaling is dispensable for adult murine hematopoietic stem cell function and hematopoiesis. Cell Stem Cell. 2009;4(6):559-567.

178. Gao J, Graves S, Koch U, et al. Hedgehog signaling is dispensable for adult hematopoietic stem cell function. Cell Stem Cell. 2009;4(6): $548-558$.

179. Siggins SL, Nguyen NY, McCormack MP, et al. The hedgehog receptor patched1 regulates myeloid and lymphoid progenitors by distinct cell-extrinsic mechanisms. Blood. 2009;114(5):995-1004.

180. Merchant A, Joseph G, Wang Q, Brennan S, Matsui W. Gli1 regulates the proliferation and differentiation of HSCs and myeloid progenitors. Blood. 2010;115(12):2391-2396.

181. Reya T, Morrison SJ, Clarke MF, Weissman IL. Stem cells, cancer, and cancer stem cells. Nature. 2001;414(6859):105-111.

182. Sims-Mourtada J, Izzo JG, Apisarnthanarax S, et al. Hedgehog: an attribute to tumor regrowth after chemoradiotherapy and a target to improve radiation response. Clin Cancer Res. 2006;12(21):6565-6572.

183. Yoshikawa R, Nakano Y, Tao L, et al. Hedgehog signal activation in oesophageal cancer patients undergoing neoadjuvant chemoradiotherapy. Br J Cancer. 2008;98(10):1670-1674.

184. Takebe N, Harris PJ, Warren RQ, Ivy SP. Targeting cancer stem cells by inhibiting Wnt, notch, and hedgehog pathways. Nat Rev Clin Oncol. 2011;8(2):97-106.

185. Song Z, Yue W, Wei B, et al. Sonic hedgehog pathway is essential for maintenance of cancer stem-like cells in human gastric cancer. PLoS One. 2011;6(3):e17687.

186. Tanaka H, Nakamura M, Kameda C, et al. The hedgehog signaling pathway plays an essential role in maintaining the CD44+CD24-/ low subpopulation and the side population of breast cancer cells. Anticancer Res. 2009;29(6):2147-2157.

187. Liu S, Dontu G, Mantle ID, et al. Hedgehog signaling and Bmi-1 regulate self-renewal of normal and malignant human mammary stem cells. Cancer Res. 2006;66(12):6063-6071.
188. Takahashi T, Kawakami K, Mishima S, et al. Cyclopamine induces eosinophilic differentiation and upregulates CD44 expression in myeloid leukemia cells. Leuk Res. 2011;35(5):638-645.

189. Li C, Heidt DG, Dalerba P, et al. Identification of pancreatic cancer stem cells. Cancer Res. 2007;67(3):1030-1037.

190. Visbal AP, LaMarca HL, Villanueva H, et al. Altered differentiation and paracrine stimulation of mammary epithelial cell proliferation by conditionally activated smoothened. Dev Biol. 2011;352(1):116-127.

191. Bar EE, Chaudhry A, Lin A, et al. Cyclopamine-mediated hedgehog pathway inhibition depletes stem-like cancer cells in glioblastoma. Stem Cells. 2007;25(10):2524-2533.

192. Clement V, Sanchez P, de Tribolet N, Radovanovic I, Ruiz i Altaba A. Hedgehog-Gli1 signaling regulates human glioma growth, cancer stem cell self-renewal, and tumorigenicity. Curr Biol. 2007;17(2):165-172.

193. Su W, Meng F, Huang L, Zheng M, Liu W, Sun H. Sonic hedgehog maintains survival and growth of chronic myeloid leukemia progenitor cells through $\beta$-catenin signaling. Exp Hematol. 2012;40(5): 418-427.

194. Domingo-Domenech J, Vidal SJ, Rodriguez-Bravo V, et al. Suppression of acquired docetaxel resistance in prostate cancer through depletion of notch- and hedgehog-dependent tumor-initiating cells. Cancer Cell. 2012;22(3):373-388.

195. Ramaswamy B, Lu Y, Teng KY, et al. Hedgehog signaling is a novel therapeutic target in tamoxifen-resistant breast cancer aberrantly activated by PI3K/AKT pathway. Cancer Res. 2012;72(19):5048-5059.

196. Steg AD, Bevis KS, Katre AA, et al. Stem cell pathways contribute to clinical chemoresistance in ovarian cancer. Clin Cancer Res. 2012;18(3):869-881.

197. Chaudary N, Pintilie M, Hedley D, et al. Hedgehog pathway signaling in cervical carcinoma and outcome after chemoradiation. Cancer. 2012;118(12):3105-3115.

198. Queiroz KC, Ruela-de-Sousa RR, Fuhler GM, et al. Hedgehog signaling maintains chemoresistance in myeloid leukemic cells. Oncogene. 2010;29(48):6314-6322.

199. Singh RR, Kunkalla K, Qu C, et al. ABCG2 is a direct transcriptional target of hedgehog signaling and involved in stroma-induced drug tolerance in diffuse large B-cell lymphoma. Oncogene. 2011;30(49): 4874-4886.

200. Lin SH, George TJ, Ben-Josef E, et al. Opportunities and challenges in the era of molecularly targeted agents and radiation therapy. J Natl Cancer Inst. 2013;105(10):686-693.
OncoTargets and Therapy

\section{Publish your work in this journal}

OncoTargets and Therapy is an international, peer-reviewed, open access journal focusing on the pathological basis of all cancers, potential targets for therapy and treatment protocols employed to improve the management of cancer patients. The journal also focuses on the impact of management programs and new therapeutic agents and protocols on

\section{Dovepress}

patient perspectives such as quality of life, adherence and satisfaction. The manuscript management system is completely online and includes a very quick and fair peer-review system, which is all easy to use. Visit http://www.dovepress.com/testimonials.php to read real quotes from published authors. 